\title{
Innovation needs deregulation: the case of taxi and private hire companies
}

\author{
Christian NASULEA \\ University of Bucharest, Bucharest, Romania \\ christian@nasulea.ro \\ Diana Florentina NASULEA \\ The Bucharest University of Economic Studies, Bucharest, Romania \\ diana@nasulea.ro \\ Stelian Mihai MIC \\ University of Bucharest, Bucharest, Romania \\ stelian.mic@miclawoffice.eu
}

\begin{abstract}
Every year seems to bring about new technologies that radically change the way we do things. New innovative business models come to life, that change the way the world works so much that a shift of mindset is required if we are to keep up. These days, the largest transport company in the world owns no cars, the largest accommodation provider owns no real estate, the largest retailer by value has no inventory of its own, and the most popular media owner creates no content. But what about the role of regulation in this brave new world? We take a look at the rivals, taxi companies and private hire transport companies (in particular Uber), to assess the need for regulation and the impact of regulation on these two contenders. Our research examines the effects of said regulation on service quality and safety, correlated with consumer opinion data. The impact of non-regulatory incentives on the two seemingly-opposed business models is discussed, thus making the logical case for increased deregulation of both taxis and private hire companies. Opening the way to innovative companies and innovative new business models, allowing them to change the world is our gateway to growth, prosperity and sustainability.
\end{abstract}

Keywords: ride-sharing, sharing-economy, innovation, deregulation, Uber.

\section{Introduction}

New technologies have made platforms such as Uber, Airbnb or Lyft very popular. Many other resources offering access to services that were before limited to personal or smallgroup use are becoming wide-spread. New models always have a tendency to bring disagreement among scholars and the sharing economy makes no exception from the rule. According to well-known scholars (Meelen \& Frenken, 2015) the sharing economy refers to consumers or companies who grant each other "temporary access to use their underutilized physical assets, possibly for money". Even though this definition may follow a different structure than most scholarly ones, we would opt for using this one as it does not restrict the wide variety of meanings attributed to this concept. The activities commonly referred to as the sharing economy are also known as collaborative consumption (Bosman, 2015) or access-based consumption.

The sharing economy is basically the expression of letting web interfaces intermediate peer-to-peer transactions between people who need services and people who are able to provide them. As using fast connections to ease activities performed by 
individuals might seem the normal evolution of 21st century society, companies operating in such a way draw the attention of regulators as these activities take place within a gray area of the existing regulatory framework (Dostmohammad \& Long, 2015). Even though not all sharing business models are being used globally, growth rates remain impressive. Credit Suisse estimates that the total value of start-up businesses activating within the sharing economy had reached $\$ 219$ billion by 2015 (Credit Suisse, 2015) and is expected to grow at a rate of $25 \%$ per year generating revenues of up to $\$ 335$ billion per year by 2025 .

These new forms of economic activities generated by the sharing economy are bringing a series of issues within existing regulatory frameworks, and regulatory bodies must find appropriate responses. Both private and public interests are pursuing the idea of making all companies from a field comply to the same rules, while not taking into consideration the innovation criteria of services derived from new technologies. For sustainable development of innovative technologies, responsiveness becomes crucial for offering these companies the chance to operate into the future (Dostmohammad \& Long, 2015)

\section{Literature review}

Research on regulations applied to services within the framework of the sharing economy usually addresses the legal issues these services might pose. Dyal-Chand (2015) uses the varieties of capitalism theory to create a model in which the inquiry into the specific institutions of this field is prioritized. Ranchordas (2015) offers suggestions for creating broader rules that would encourage innovation but at the same time impose some legal requirements adaptable to sharing economy practices. Other studies (Biber et. al, 2017; Miller 2015) have also focused on creating theoretical models from the perspective of lawmaking in order to assess the main principles that should create a comprehensive framework for many of the services within the sharing economy. We offer a multidisciplinary approach focused only on the issue of private-hire companies with the purpose of firstly identifying the problems of adopting rigid regulations and secondly, shaping some possible solutions. For this second objective, we use the theoretical framework described by Miller (2015) and Dyal-Chand (2015) and we apply it to the case of private-hire companies in Romania.

\section{Methodology}

This paper tries to analyze the potential challenges brought by the sharing economy upon existing regulatory frameworks. We will use the case of private hire taxis like Uber vs. regular taxis to offer a series of coordinates meant at limiting the uncertainty and possible risks attached to the sharing economy. From this perspective, this paper aims to answer the following question: is there a way to encourage innovative technologies and business while also ensuring customer safety? We will therefore firstly discuss the characteristics of these innovative businesses in order to assess if they are different from so-called traditional market activities, with a focus on the uncertainties characterizing these new fields.

The second part of the research will focus on regulatory practices using a case-study on customers' opinions related to Uber's services. In order to assess the perceptions of Uber users on safety-related issues we have applied a questionnaire on 150 individuals. The results are analyzed from an interdisciplinary approach focused on explaining the problems 
arising from applying traditional regulation to private-hire companies and offer a series of coordinates for possible solutions that could lead to a sustainable innovative future for these businesses.

\section{Results and discussions}

The sharing-economy does not exclusively refer to for-profit activities. Technological platforms allow for a wide variety of services to which people voluntarily contribute. Think about the main website accessed for acquiring information, Wikipedia, or online forums, Quora being maybe the most successful example in this case, or platforms dedicated to programmers who help each other solve coding issues with no other remuneration than the acknowledgments of one's peers. These activities do not constitute the purpose of our paper, but similarly to these, for-profit activities within the sharing-economy are characterized by a series of specific attributes.

Firstly, the sharing economy or the collaborative economy marks a change of the organizational structures made possible by technology (Witt, Suzor, \& Wikstrom, 2015). The sharing economy offers services that work by exploiting underused capacity in privately owned goods (Witt, Suzor, \& Wikstrom, 2015). Because of this, the costs of becoming a provider of these services is very low as it involves a resource that one already owns. Even though supply might increase easily, the resources involved in this process still have a purchase price that is high enough to incentivize consumers to rent access to them. These two factors mean that suppliers can still earn money by providing services within the sharing economy, while customers can save money by using resources owned by their peers, at a lower price than that of using a traditional service provider.

Secondly, all these activities are intermediated though the Internet. While other collaborative services, such as hosting strangers in your home in the case of Romanian seaside resorts, or intermediating good deeds to unlucky individuals through the Church represent peer-to-peer activities, they do not belong to what we, today, call the sharing economy, as they lack the fundamental aspect determining the specificity of these new businesses, which is, the virtual space.

\section{Speed, convenience, ease of use and other gains}

Specific to these services within the sharing economy is also the speed resources can be accessed at (Dyal-Chand, 2015). One can find a ride or a host within seconds, and in a context where time is the ultimate resource, the advantages of these services become obvious. Furthermore, these markets often have a comparative advantage to their counterparts by providing more interesting features. Think about the UberLux function which enables you to ride in a Tesla S or in a Mercedes-Benz S class as well as many other well-known brands and high-end models at convenient prices (Uber, 2014). From this perspective, peer-to-peer businesses make most of their profit not from providing simple services but by offering memorable experiences, this being the other major difference between traditional services and the sharing market. Directly related to the former aspects discussed is the greater service variety offered within the sharing economy. For example, Airbnb enables users to rent anything from a room in a castle to a tree house in the woods to a modern condo in the city center.

On the supply side, the main aspect relates to the lower transaction costs of sharing privately-owned and underutilized resources (Dyal-Chand, 2015). The most attractive 
feature for suppliers is definitely the fact that online platforms follow algorithms aimed at determining market demand, advertising homes according to customers' needs and intermediating deals and payments. This solves the issue of having to outsource and pay for advertising and securing online payments to different companies, especially for those who are not computer-savvy. Furthermore, even though suppliers still pay taxes, the amount they give is smaller, but more important, easier to transfer then in the case of proper companies. For example, Uber offers drivers the possibility to work with a registered company from the driver's area, for those people who do not own a business themselves. Money still gets transferred for taxes, and suppliers do not need to carry the burden of complicated accounting.

\section{Assuring safety through review systems.}

Online peer-to-peer activities were made possible through the review system. This feedback is what basically allows for transactions and access between strangers. From this perspective, the sharing economy is not based on blind and voluntary cooperation, but on supervised exchange. Both Uber and Airbnb give the possibility to rate both the supplier and the consumer, eliminating the possibility of fraud, meaning that only people that used a certain service coming from a certain supplier can rate the latter and vice-versa. Furthermore, both the supplier (driver or host) and customer will see who the person providing the service is, what other people think about him/her, how good his/her services are and much more. Compared to regular services, these activities within the sharing economy go further into excluding the possibility of being an anonymous user or provider. Uber also offers the possibility of sharing one's location with friends or family, allowing for an even greater level of security and safety (Uber, 2017).

There are other specific aspects characterizing the sharing economy that were not discussed here. We have chosen to focus on those at risk, those which might change in case of over-regulation through legislation being applied to the market. Often the unintended consequences of regulation will outweigh the potential benefits. In the following section, we will address some of the failures of regulatory bodies in this field while also looking at the main arguments against ride-sharing solutions.

\section{Against private-hire taxis?}

The main argument against ride-sharing services refers to not following the competition's rules. A Huffington Post blog post argues that "Uber not only flaunts regulation, it thinks it has the right to go underregulated" (Hobica, 2016). Considering this argument, we believe a distinction needs to be made. Firstly, ride-sharing services do not go unregulated, but they are not over-regulated either, at least in most countries. As any other company, Uber Inc needs to comply to all regulations imposed by the country in which it is registered, and therefore, in which it pays taxes. Furthermore, in Romania, drivers too need to either register as a PFA (authorized sole trader) or work with a locally registered and authorized company, and therefore pay taxes to the government in both cases. According to a public statement of Uber Romania's general manager Nicoleta Schroeder, $80 \%$ of the revenues of from a ride go to the driver, the rest being accounted for taxes and a fee Uber charges their drivers (Ghenciu, 2017).

The other main argument against ride-sharing refers to the fact that it does not ensure the safety of its customers. As researchers we must understand: compared to what? 
In Romania, traditional taxis are required to go through a licensing procedure with local town halls. These procedures are not only time-consuming, but very costly, as town halls only allow for a limited number of taxi licenses per year. Given the great number of documents, bureaucracy and corruption involved in the process, taxi licenses are usually sold online for prices of up to 10.000 Euros. Safety checks play a minimal or inexistent part in this process. What really needs to be considered here is whether regulations imposed on taxis really do ensure their safety? If they do not, then imposing the same regulations to Uber drivers would not enhance safety, and instead it would only deny access to the system to a number of potential drivers. Uber is already making drivers undergo a series of safety check procedures, they are obliged to bring a criminal record, a record of traffic violations as well as proof that they are paying their taxes. Furthermore, the feedback aspect is crucial in determining if people liked the experience they had with the driver. The potential for fraud still exists, but it would exist regardless of how many regulations are imposed.

\section{Case Study - Uber in Bucharest}

As the main problem concerning Uber is related to safety, we have decided to conduct a survey with the purpose of finding out how safe users feel in their experiences with Uber. We used a questionnaire in order to determine the preferences of Uber users, as we believed this should be a determinant factor when adopting regulations that affect not only the company's policies but also user's experiences with the services provided.

The survey was conducted in November 2017 and was applied to 150 individuals. The target population was comprised of 113 respondents living in Bucharest, Romania of which 50\% were between 25-34 years old, 30\% - 18-24 years old, 11\% - 35-44 years old, and the rest of $9 \%$ was over 45 years old or under 18 . We believed Uber users aged between 18-34 years old to be representative for the general population using ridesharing services in Bucharest. Regarding other demographic data about the target group, $46 \%$ of the respondents had already earned a Master's degree, 32\% a bachelor's degree, $16 \%$ were high school graduates and 3\% had earned a Doctoral degree. Regarding employment status $63 \%$ of the respondents were employed for wages, $10 \%$ self-employed and $22 \%$ were students.

Moving on to their experience with Uber, over $5 \%$ of the respondents were frequent users of Uber services, meaning they had used it more than three times in the last month. Within our target group we have discovered that Uber users were/are taxi users as well but almost $90 \%$ of them prefer Uber as a transportation service, and more than $85 \%$ of the respondents highly agree or agree they are generally satisfied with their relationship with Uber.

As the purpose of the paper refers to issues regarding safety and regulations, our questionnaire included three questions meant to determine if Uber users feel safe using this particular ridesharing service. Respondents were asked to select one of the following six answers (highly agree, agree, neither agree nor disagree, disagree, highly disagree) for each statement:

1. I feel safe as a customer riding with Uber

2. Uber (and their policies) has done an adequate job of keeping customers safe in Uber vehicles.

3. I would feel safer if UBER drivers would undergo the same licensing procedures as taxi drivers 


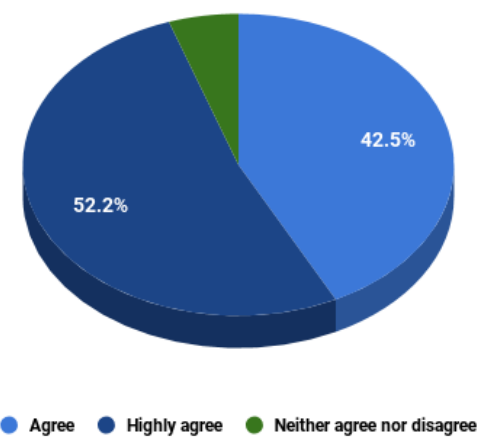

PICBE | 656

Figure 1. I feel safe as a customer riding with Uber

Source: Authors' own research.

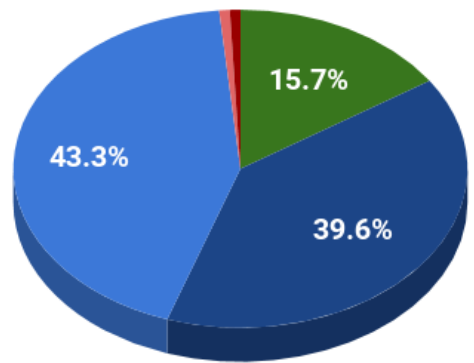

Neither agree nor disagree Highly agree Agree Disagree Highly Disagree

Figure 2. Uber (and their policies) has done an adequate job of keeping customers safe in Uber vehicles

Source: Authors' own research.

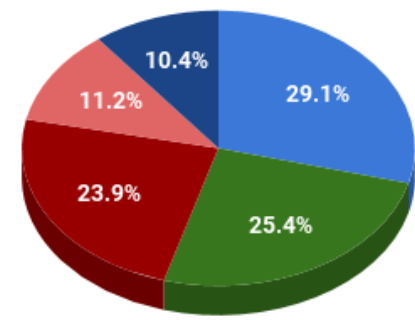

Agree Neither agree nor disagree Highly Disagree Disagree Highly agree

Figure 3. I would feel safer if Uber drivers would undergo the same licensing procedures as taxi drivers

Source: Authors' own research. 
Figure 1 and Figure 2 show a positive perception of respondents in correlation with the safety factor when using Uber's services. The majority of respondents either agrees or highly agrees to the fact that they feel safe as customers riding with Uber showing also that Uber's safety policies have a positive impact on their clients. This is important especially because one of the main concerns emphasized by their competition, taxi companies, relates to safety. Our respondents however, seem to associate safety with Uber.

For the third statement, answers seem to be all over the spectrum. Although the majority of respondents felt safe riding with Uber, it seems like a significant part of the target group 40\% consider they would feel safer if Uber drivers would undergo the same licensing procedures as taxi drivers. Given the discrepancy within the answers to this last statement (Figure 3) and the previous ones we can draw some hypotheses.

H1. Uber users associate the idea of licensing with safety. This might be happening because of a series of factors. First of all, public discourse against Uber promotes the idea of ridesharing companies not asking for vehicle inspections, insurance and background checks on the drivers, and not paying taxes (Agerpres, 2016). Indeed, ridesharing drivers might pose a risk to passengers and these issues are not necessarily predictable within the screening process Uber is performing on its drivers. However, if we look specifically at what can discourage bad behavior of licensed taxi drivers we cannot find a deterrent, other than the time-consuming bureaucratic process of obtaining all authorizations. As a private competitive company, Uber has all incentives to stop unfortunate events from happening. For example, in the US, Uber's screening of drivers goes much further then taxi companies, as they correlate data on drivers with the Multi-State Criminal Database and Uber plans to examine data from other sources as well, for example the Departments of Corrections and the Administrative Office of the United States Courts (Feeney, 2015). The insurance might represent a safety risk, as rightfully some might ask what would happen in case of an accident. Insurance is covered from the moment the passenger starts the ride to the moment he/she arrives to the destination, according to Uber's communications manager in Romania (Prelipceanu, 2017). Safety issues can still be a problem, but they aren't solely a problem of ridesharing companies. However, technology develops in such a way that new solutions for overcoming potential risks become available on a large scale, and companies wishing to operate in the future and remain on the market will for sure secure their position by taking full advantage of all available possibilities to deliver better services.

H2. Licensing is not relevant for users' safety. The results also suggest a significant group (25\%) considering that licensing doesn't in fact, change anything, while a similar percentage highly disagree to licensing making it safer for customers. Given the results from the first two statements, we can conclude that Uber users feel safe with its services at the moment. In fact, consumers do not necessarily care how their safety assured as long as it is. Maybe safety procedures differ from the "traditional" ones, but they still exist, and consumers seem to be happy with them. The rapid growth of Uber use in Romania shows that consumers are far from being satisfied with the current taxi service, which, even though heavily regulated, does not seem to perform very well.

Towards a new model of more general and equitable regulations

The sharing economy in general and ride-sharing services in particular are still functioning within a grey area of the legislative system. However, as they stop being considered new \& innovative services, different countries and institutions have approached the issue from different perspectives. Countries such as Bulgaria, Denmark, Hungary, or 
cities like Vancouver, Austin or more recently, London have forbidden Uber. (Rhodes, 2017). These decisions might look politically popular to areas with a constituency afraid of change (Miller, 2015). However, long-term strategies cannot exclude the sharing-economy and still provide for effective and business-friendly environments. Furthermore, not discussing the new issues brought by these ridesharing services is not sustainable either, as taxi companies are right to complain they need to compete with somebody who doesn't play by the same rules (Feeney, 2015). As we have discussed in the first section, ridesharing services are indeed different from regular taxi services, so the solution should not be the application of the same highly bureaucratized process to Uber as well. The sharing economy is here to stay (Miller, 2015) and its particularities must be determinant in creating appropriate legislative frameworks.

Firstly, the base principle that should be applied in dealing with all these issues should be to adopt regulation that favors coexistence of many transportation alternatives, while also leaving room for new ones to develop. For this purpose, services should be properly defined. Is Uber a website provider or a taxi company. Here, the major issues are figuring out if Uber internalizes enough of the functions provided by regular taxi companies, like the ownership of key assets or control over the assignment of drivers to those assets. If Uber is internalizing all these functions then it should be regulated as a taxi company, but if it is only a network of independent drivers, then it should be regulated accordingly (Dyal-Chand, 2015). From this perspective, perhaps companies activating within the sharing economy should be considered intermediaries and comply to rules intended for intermediaries.

Secondly, in order to create a competitive framework designed to offer increasingly better services for customers, some of the regulations applied to traditional transportation companies should be eliminated if they do not serve their final purpose, and some of them do not, as is the case with illegally obtained taxi licenses as previously discussed.

Thirdly, the nature of the contractual agreement between the parties involved should be established by the legal framework. According to Dyal-Chand (2015) Hall \& Soskice (2001) suggest that:

Because of the many contingencies that can arise in close interfirm relationships involving joint research or product development, tightly written, formal contracts are often inadequate to sustain such relationships. However, the German courts permit unusually open-ended clauses in interfirm contracts on the explicit condition that these be grounded in the prevailing standards of the relevant industry association. Germany uses the institution of relational contracting to complement the work of business associations. It provides space for such associations to accomplish a certain level of what U.S. regulators might describe as self-regulation.

This solution would therefore bring more choices and possibilities in setting up standards that are accepted by both the industry and the customers, while also lowering the costs of writing formal contracts by accepting informal contracts (Dyal-Chand, 2015).

The fourth principle to be considered is directly related to ensuring safety. To create a regulatory framework that is not over-bureaucratized several issues need to be addressed. First of all, consumers should be aware of all potential risks before using a service. This translates to determining who is liable in cases of assault or other types of bad behavior on the part of both the driver and the passenger. Perhaps a solution in this sense would be to ask drivers to carry full liability in case of complaints from the customer, which is a matter that currently would be treated very differently if the driver was performing under a sole-trader license, or as the representative of a firm. All these issues should be 
addressed and solved in such a way that part-time drivers would not be discouraged from working with Uber and consumers would be assured of their safety. Regulations could therefore come from a forum of Uber representatives, customers, and local-authorities working together to find the best solution. Uber could also communicate to public institutions when screening the drivers, as in the US example. This might reduce the potential risks and make users feel safer when using its services.

PICBE $\mid 659$

\section{Conclusion}

Regulating the sharing economy might be inevitable, but all these innovative services represent an opportunity to rethink regulation itself. Solutions should not fall into the cliché of using traditional patterns, but they should uncover the path towards new approaches. Regulators should address more neutral ways of designing regulatory frameworks. However, solutions should not only be applied to these new services, but also to so-called traditional services, in order to create a competitive market for all parties involved.

Determining how things should work needs to consider both providers' and consumers' opinions, as they will be the ones most affected by any measures applied. Treating all these different services as ride-sharing services could help create a more equitable framework. Ensuring safety is a key concern for everyone involved and should be a determining factor in creating regulations.

This paper has discussed potential problems arising from applying the existing regulatory framework for transportation companies on private-hire services. The key issues in need to be address revealed by our study refer to users' perceived safety. Our case-study was limited to Uber users and their experiences with the company's services. The results of our analysis brought up four different principles that need to guide the efforts of creating long-term permissive regulation-making process. Defining services, establishing a fair and equitable framework for all companies, acknowledging informal contracts and assuring safety are therefore the determinant aspects in creating a regulatory environment that will allow companies to innovate in a sustainable manner.

\section{References}

Dostmohammad, S., \& Long, J. (2015). Regulating the Sharing Economy. Retrieved from Canadian Association of Programs in Public Administration: https:/cappa.ca/wp/ wpcontent/uploads/2017/06/DostmohammadLong_RegulatingtheSharingEconomy. pdf

Agerpres. (2016). COTAR: ANAF a cerut Uber o listă cu toți utilizatorii; un șofer din Capitală a încasat 60.000 lei în 2015. Bucharest, Romania. Retrieved from https://www.agerpres.ro/economie/2016/11/25/cotar-anaf-a-cerut-uber-o-listacu-toti-utilizatorii-un-sofer-din-capitala-a-incasat-60-000-lei-in-2015-11-03-20

Bosman, R. (2015). Fast Company. Retrieved from Fast Company: http://www.fastcoexist.com/3022028/the-sharing-economy-lacks-a-shareddefinition

Biber, E.. Light, S., Ruhl, J.B., Salzman, J. (2017). Regulating Business Innovation as Policy Disruption: From the Model T to Airbnb. Vanderblit Law Review, 70(5), 1561-1626.

Credit Suisse. (2015). Global Equity Themes. The Sharing Economy. Retrieved from https://research-doc.credit- 
suisse.com/docView?document_id=x657090\&serialid=\%2BoJISdkXI8WqPDLKIKH5 1 yO3NdPKCzCWPXEKeyF0dQo\%3D

Dyal-Chand, R. (2015). Regulating Sharing: The Sharing Economy as an Alternative Capitalist System. Tualne Law Review, 90(2), 241-309.

Feeney, M. (2015). Is Ridesharing Safe? Washington DC: Cato Institute. Retrieved from https://object.cato.org/sites/cato.org/files/pubs/pdf/pa767.pdf

Ghenciu, T. (2017). Cat castiga un sofer Uber intr-o luna. Digi24. Retrieved 11 28, 2017, from http://www.digi24.ro/emisiuni/exclusiv-online/24-minute/managerul-uberromania-invitata-la-24-de-minute-728765

Hall, P., \& Soskice, D. (2001). Introduction to Varieties of Capitalism: The Institutional Foundations of Comparative Advantage. Oxford: Oxford.

Hobica, G. (2016). 7 Reasons I'm Not On Board With Uber. Huffington Post. Retrieved from https://www.huffingtonpost.com/george-hobica/5-very-good-reasons-whyi_b_5406643.html

Meelen, T., \& Frenken, K. (2015). Fast Company. Retrieved from Fast Company: https://www.fastcompany.com/3040863/stop-saying-uber-is-part-of-the-sharingeconomy.

Miller, S. (2015). First Principles for Regulation the Sharing Economy. Harvard Journal on Legislation, 53, 147-202.

Prelipceanu, M. (2017). Cum răspunde UBER acuzațiilor taximetriștilor. Bucharest, Romania: RFI Romania. doi:http://www.rfi.ro/asculta-la-rfi-ro-94735-cumdemonteaza-uber-acuzatii-taximetristi

Ranchordas, S. (2015). Does Sharing Mean Caring? Regulation Innovation in the Sharing Economy. Legal Studies Research Paper Series, 16(1), 1-63.

Rhodes, A. (2017). Uber: Which Countries Have Banned the Controversial Taxi App. Retrieved from http://www.independent.co.uk/travel/news-and-advice/uber-bancountries-where-world-taxi-app-europe-taxi-us-states-china-asia-legala7707436.html 